\title{
Fatigue Prediction of Porous Magnesium Bone Scaffold Using Finite Element Method
}

\author{
Risky Utama Putra ${ }^{1}$ Akbar Teguh Prakoso ${ }^{1}$ Amrillah Nugrasyah ${ }^{1}$ Darmawi $^{1}$ Amir \\ Putra Md Saad ${ }^{2,3}$ Ardiyansyah Syahrom ${ }^{2,3}$ Hasan Basri ${ }^{1, *}$ \\ ${ }^{1}$ Mechanical Engineering Master Study Program, Faculty of Engineering, Universitas Sriwijaya, Indralaya 30662, \\ Ogan Ilir, South Sumatera, Indonesia \\ ${ }^{2}$ Department of Applied Mechanics \& Design, School of Mechanical Engineering, Faculty of Engineering, Universiti \\ Teknologi Malaysia, Skudai, Johor, Malaysia \\ ${ }^{3}$ Medical Device and Technology Center (MEDITEC), Institute of Human-Centered Engineering (iHumEn), \\ Universiti Teknologi Malaysia, Skudai, Johor, Malaysia \\ *Corresponding author. Email: hasan basri@unsri.ac.id
}

\begin{abstract}
The purpose of this study was to determine fatigue in a porous magnesium bone scaffold. It applies finite element simulation in assessing bone scaffolding's fatigue behaviour with variations in axial loading based on physiological activities in humans. By applying the boundary conditions to the solid mechanics model and fatigue simulation, it subjects each specimen to a different loading of $1000-3500 \mu \varepsilon$, which gives the bone scaffold displacement variations. The simulation results of fatigue life for the porosity of $30 \%, 41 \%$, and $55 \%$ show that the greater the loading, the lower the number of failure cycles on the porous magnesium bone scaffold. For a porosity of $30 \%$ with a load of $1000-3500 \mu \varepsilon$, it produces the number of failure cycles from $3.99 \times 10^{22}-3.61 \times 10^{16}$.
\end{abstract}

Keywords: Bone scaffolding, magnesium, porosity, finite elements, fatigue

\section{INTRODUCTION}

When implanted into the human body, the porous $\mathrm{Mg}$ bone scaffold will immediately come into contact with the cell bone and biomechanically adjust to the mechanical load of repetitive (cyclic) movements in human physiological activities. The bone scaffold will lose its strength because of the bone scaffold's mechanical response from cyclic movements in the bone's physiological activities. It is complicated to predict the lifespan of a bone scaffold, which will fail because of exhaustion and cause the scaffold struts to decrease.

In previous studies, researchers have performed experimental fatigue tests for PLA, zinc, and ferrous materials [1][2][3][4]. However, to examine the porous $\mathrm{Mg}$ bone scaffold's fatigue behaviour when implanted in the bone is very complicated and almost impossible to do with experimental testing. Therefore, in this study, the authors carry out a finite element simulation approach using COMSOL Multiphysics 5.4 software with a solid mechanics and fatigue simulation method.
Studying the relationship between human physiological load variations and fatigue is very important. Its mechanical behaviour largely determines the fatigue life of the bone scaffold structure. By knowing the load changes, the bone scaffold's mechanical behaviour and fatigue life, when implanted in the bone tissue, can be predicted and controlled. We can only verify changes in the load of the $\mathrm{Mg}$ porous bone scaffold structure to the mechanical structure behaviour and fatigue life because of the bone tissue degradation phenomenon through a combination of computational approaches. We expect these results to provide precise and accurate results in determining the fatigue cycle's value in a porous bone scaffold.

\section{MATERIALS AND METHOD}

\subsection{Preparation of test specimens}

Commercially available pure magnesium rod (25.4 $\mathrm{mm}$ diameter and $99.9 \%$ purity, Goodfellow Inc., Cambridge, UK) cubed (10x10x10) specimen using a CNC machine (HAAS, USA) [5] (see Figure 1). The 
material tested has the following chemical composition, as shown in Table 1.

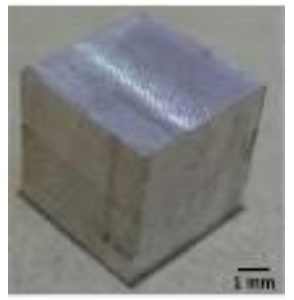

Figure 1 A photograph of cuboid magnesium with $99.9 \%$ purity

Table 1. The chemical composition (in wt.ppm) of the commercially pure $\mathrm{Mg}$ with $99.9 \%$ purity

\begin{tabular}{|c|c|c|c|c|c|c|c|}
\hline Element & $\mathrm{Al}$ & $\mathrm{Zn}$ & $\mathrm{Fe}$ & $\mathrm{Cu}$ & $\mathrm{Mn}$ & $\mathrm{Ni}$ & $\mathrm{Si}$ \\
\hline Wt.ppm & 70 & $<20$ & 280 & 20 & 170 & $<10$ & 50 \\
\hline
\end{tabular}

\subsection{Mechanical Properties}

We performed monotonic testing at room temperature in a universal testing machine (FastTrack 8874, Instron Norwood, USA). We tested the solid magnesium specimens for compression at a strain rate of $0.005 \mathrm{~mm} / \mathrm{s}$ and a load cell of $25 \mathrm{kN}$ to get their mechanical properties. Practical methods used to predict fatigue life in specimens are fracture mechanics, strain life and a stress life. The strain-based model is suitable for predicting fatigue at low cycle fatigue. We used the universal testing machine (FastTrack 8874, Instron Norwood, USA) for cyclic loading performed under strain control. We performed cyclic loading using strain-controlled software (Wave Matrix TM Dynamic Material Testing Software, Instron, USA).

Normal running conditions average around $1-3 \mathrm{~Hz}$, so it subjects the sample to compressive loading on a 2 $\mathrm{Hz}$ sine wave [6][7] and loading ratio of $\mathrm{R}=0.1$. From the experimental test, a typical hysteresis loop stressstrain curve of compressive loading using straincontrolled and finally strain-life curve can be generated using combination Basquin and Coffin-Mansion equation (1),

$\frac{\Delta E}{2}=\varepsilon_{a}=\frac{\Delta \varepsilon_{g}}{2}+\frac{\Delta E_{p}}{2}=\frac{\sigma_{f}^{\prime \prime}}{E}\left(2 N_{f}\right)^{b}+\varepsilon_{f}^{f}\left(2 N_{f}\right)^{C}$

Where,

$$
\begin{array}{lll}
\frac{\Delta \varepsilon}{2} & : & \text { Total strain amplitude } \\
\frac{\Delta \varepsilon_{e}}{2} & : & \text { Elastic strain amplitude } \\
\frac{\Delta \varepsilon_{p}}{2} & : & \text { Plastic strain amplitude } \\
\varepsilon_{f}^{a} & : & \text { Fatigue ductility exponent }
\end{array}
$$

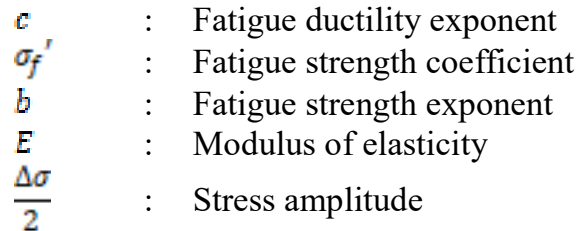

The straight-line elastic part can be changed to the following equation (2)

$\frac{\Delta \sigma}{2}=\sigma_{a}=\sigma_{f}^{\prime \prime}\left(2 N_{f}\right)^{b}$

This equation is known as Basquin's equation, in addition

$\frac{\Delta \varepsilon_{g}}{2}=\varepsilon_{f}^{r}\left(2 N_{f}\right)^{e}$

Which is known as the Coffin-Manson relationship, namely the intersection of the elastic line and the plastic line, which is called the transition fatigue life, is shown in the following equation (4),

$2 N_{t}=\left(\frac{\varepsilon_{f}^{f}}{\sigma_{f}^{s}}\right)^{\frac{1}{b-x}}$

For lives less than the deformation is counted as mainly plastic; however, for more comprehensive data and more extensive than the deformation is mainly elastic. The strain-based approach support high-cycle and low-cycle fatigue; this approach also supports longlife processes that small plastic strain would be presented. Here, plastic strain from strain-life data will be removed, and just Basquin's equation will remain. A strain-based approach widely applies in low-cycle and high-cycle components. After fitting data to get all strain-life properties, these properties, stress and plastic strain are counted as independent variables and fatigue life as the dependent variable as shown mathematically in equation (5) below,

Fatigue life $=f\left(\sigma_{f}{ }^{o}, \varepsilon_{f}^{o}, b, c\right.$, stress, strain $)$

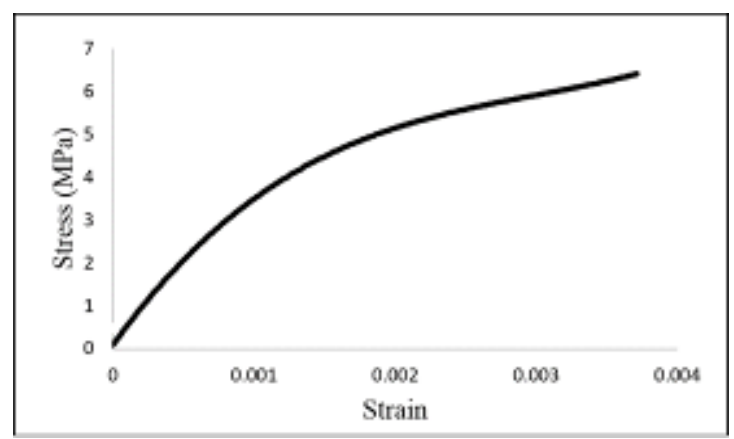

Figure 2 Stress-Strain curve from experimental testing 


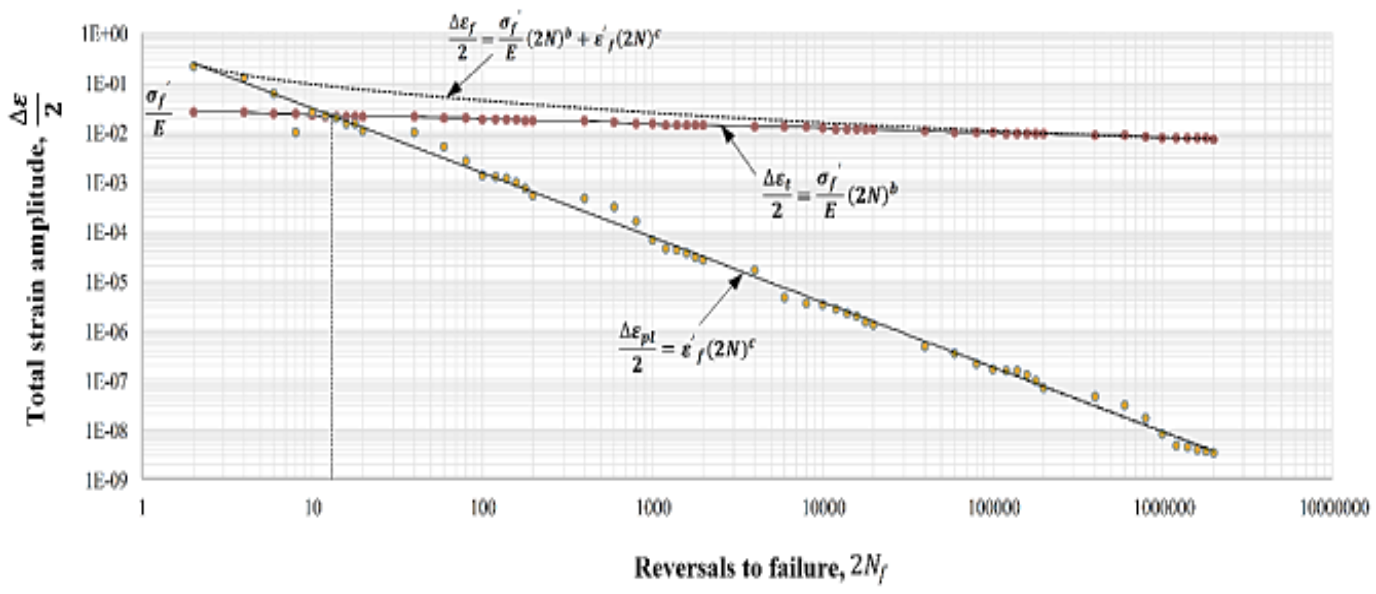

Figure $3 \mathrm{~S}-\mathrm{N}$ curve of strain-based method from experimental testing

Figure 2 and Figure 3 the mechanical properties of $\mathrm{Mg}$ and its fatigue properties can be tabulated in Table 2.

Table 2. Mechanical Properties of magnesium used in FEA.

\begin{tabular}{|l|l|}
\hline Mechanical Properties & value \\
\hline Monotonic Properties & \\
\hline Young Modulus, E $(\mathrm{GPa})$ & $3.5 \mathrm{GPa}$ \\
\hline Poisson's ratio & 0.35 \\
\hline Yield Strength, $\sigma_{y}(\mathrm{MPa})$ & 147 \\
\hline Kinematic tangent modulus $K_{T \text { hin }}$ & $0.05 \mathrm{E}$ \\
\hline Fatigue Properties & \\
\hline Fatigue ductility coefficient, $\varepsilon_{f}^{v}$, & 0.425 \\
\hline Fatigue ductility exponent, $c$ & -1.3 \\
\hline $\begin{array}{l}\text { Fatigue strength coefficient, } \\
\sigma_{f}^{*},(\text { MPa })\end{array}$ & 180 \\
\hline Fatigue strength exponent, $b$ & -0.09 \\
\hline
\end{tabular}

\subsection{Fatigue simulation using FEA approach}

Finite Element Analysis (FEA) is a numerical approach to analyze the mechanical behaviours of a porous scaffold, such as structural stiffness and fatigue life [8][9]. The advantage of FEA is its repeatability, and we can use it to replicate the actual test. For example, a similar model can be used repetitively to conduct different simulations, and this is not possible with destructive experimental tests. This ability opens a vast opportunity for scaffold sample to be optimized, such as in morphological parameters.

\subsubsection{Geometry and Finite Element Mode}

The finite element model of three different porosity of BCC structure was generated $(31 \%, 41 \%, 55 \%)$ following the range of porosity $(25 \%-90 \%)$ of cancellous bone structure [10][11]. These structures' geometry was labeled as models $\mathrm{A}, \mathrm{B}$, and $\mathrm{C}$ that indicate their porosities (see Figure 4). The morphological indices of the model, including porosity and surface area, were determined using CAD models and presented in Table 3 .

Table 3. Details sample porous magnesium scaffold specimens [12] [13].

\begin{tabular}{|c|c|c|c|c|}
\hline Sample & Porosity & $\begin{array}{c}\text { Surface } \\
\text { Area }\left(\mathrm{mm}^{2}\right)\end{array}$ & $\begin{array}{c}\text { Volume } \\
\left(\mathrm{mm}^{3}\right)\end{array}$ & $\begin{array}{c}\text { Surface area } \\
\text { per volume } \\
\left(\mathrm{m}^{-1}\right)\end{array}$ \\
\hline$A$ & $30 \%$ & 189.30 & 52.87 & 3580.48 \\
\hline$B$ & $41 \%$ & 209.81 & 44.57 & 4707.43 \\
\hline$C$ & $55 \%$ & 225.75 & 33.83 & 6673.07 \\
\hline
\end{tabular}

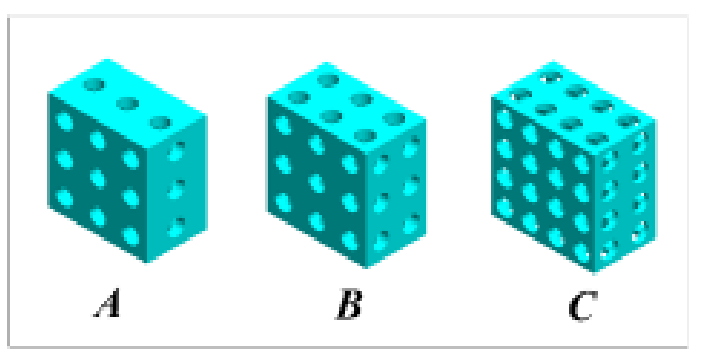

Figure 4. Snapshot of three different morphologies of bone scaffold models [20]

\subsubsection{Boundary condition and material input}

In the following step, the commercial software (COMSOL Multiphysics software, Burlington, USA) was used to simulate a porous scaffold model's stress distribution and fatigue life. The resulting numerical three-dimensional contains tetrahedral elements. The boundary condition of the FEA used in this simulation is 
shown in Figure 5. It defines the prescribed boundary condition of displacement on the top surface to simulate the uniaxial load because of the bone's mechanical loading [14]. Besides, a zero-displacement boundary condition is assigned to the opposite surface in its normal. Nodes included in this boundary condition are confined only in the $y$-direction but can move freely inside the $\mathrm{x}-\mathrm{z}$ plane. The model is fixed in the $\mathrm{y}$ direction at the bottom, and a load-based strain 1000$3500 \mu \varepsilon$ is applied to the upper surface according to the variation in the mechanical load of the bone [14] [15]. The magnesium's nonlinear-elastic/plastic material behaviour was modelled with: $3500 \mathrm{MPa}$ as the elastic modulus, a Poisson's ratio of 0.35 , and kinematic tangent modulus of $0.05 \mathrm{E}$.

For fatigue analysis, it performs fatigue simulation using full elastoplastic analysis with a combination of Basquin and Coffin-Manson equations to predict fatigue life in low and high cycle fatigue areas.

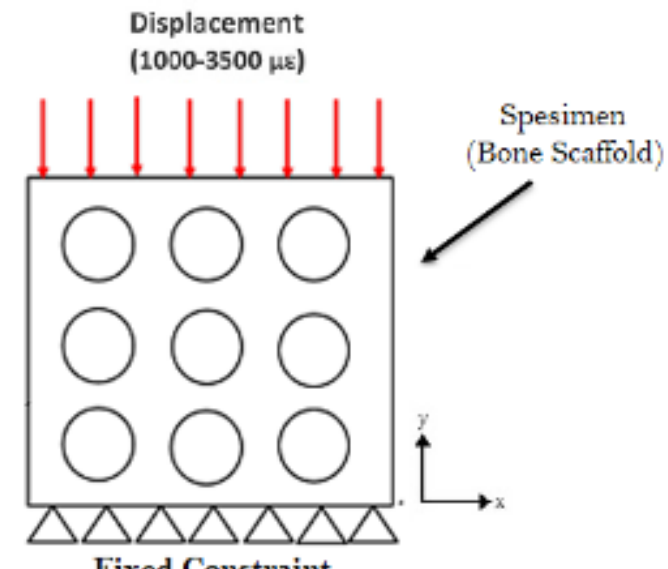

Figure 5 Boundary conditions schematic diagram

\subsection{Mesh Convergence}

It also performed a mesh sensitivity study in order to minimize numerical error during the fatigue simulations. The meshes generated for the numerical models investigated are based on tetrahedral elements. Mesh sensitivity analysis suggests that the meshes of about 80,000 elements are sufficient to produce accurate results compared to meshes with many elements 10,000 to 4,000, and the value of $\mathrm{Nf}$ still the same with 200,000 number of elements (see Figure 6).

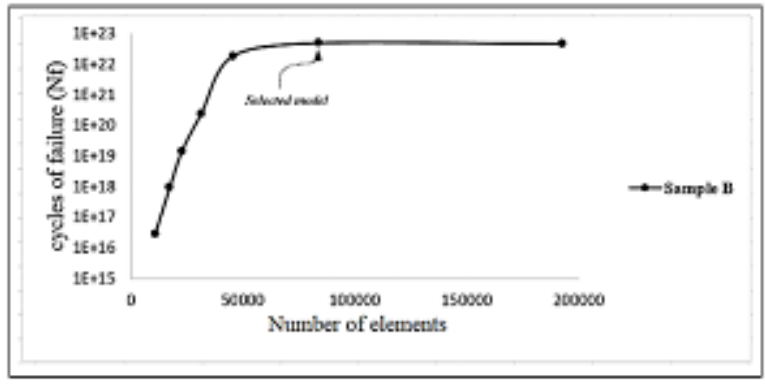

Figure 6 Convergence study for fatigue simulation

\section{RESULTS AND DISCUSSION}

\subsection{Stress Distribution on Bone Scaffold}

Finite element analysis simulation with physical studies of solid mechanics will show the stress distribution on a porous magnesium specimen model. It shows contour plots on the stress distribution in various colours, where the red colour shows the high-stress distribution level, and the blue colour shows the lowest stress distribution level in porous magnesium specimens (see Figure 7). The load given is the displacement that occurs in the cancellous bone when physiological activity occurs. It is this load that causes the different distribution of stress on the cancellous bone.

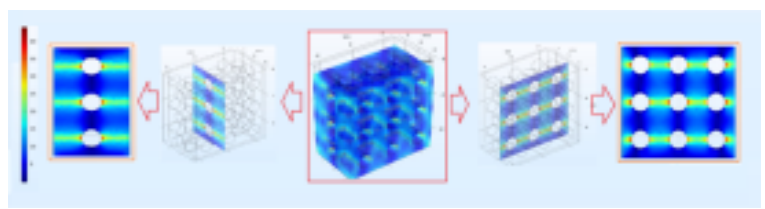

Figure 7 Stress distribution on bone scaffold

\subsection{Simulation results using the fatigue method}

We need the simulation produced by the fatigue method to analyze structural fatigue, namely the fatigue cycle. It bases the resulting simulation on three load variations in displacement: magnitude, $0.005 \mathrm{~mm}, 0.01$ $\mathrm{mm}$, and $0.0175 \mathrm{~mm}$. It will display the simulation results through a graphical table and visualized in 2 dimensions (see Figure 10). It carried the prediction of fatigue failure and plastic stress on porous magnesium out using fatigue analysis software. Table 4, Figure 8 , and Figure 9 show the fatigue failure of the porous scaffold before degradation with variations of samples $\mathrm{A}, \mathrm{B}$, and $\mathrm{C}$ with displacement variations of 1000, 2000, and $3500 \mu \varepsilon$. 
Table 4. The relationship of porosity and displacement to the fatigue life of porous magnesium

\begin{tabular}{|c|c|c|}
\hline \multirow{2}{*}{ Sample } & $\begin{array}{c}\text { Displacement } \\
(\boldsymbol{\mu \varepsilon})\end{array}$ & $\begin{array}{c}\text { Cycles of failure } \\
(\mathbf{N f})\end{array}$ \\
\hline \multirow{3}{*}{$\begin{array}{c}\mathbf{A} \\
\text { (Porosity 30\%) }\end{array}$} & 1000 & $3,99945 \mathrm{E}+22$ \\
\cline { 2 - 3 } & 2000 & $1,80717 \mathrm{E}+19$ \\
\hline \multirow{2}{*}{ B } & 3500 & $3,60579 \mathrm{E}+16$ \\
\cline { 2 - 3 } (Porosity 41\%) & 1000 & $5,09331 \mathrm{E}+22$ \\
\cline { 2 - 3 } & 2000 & $2,30144 \mathrm{E}+19$ \\
\hline \multirow{2}{*}{\begin{tabular}{c} 
Corosity 55\%) \\
\cline { 2 - 3 }
\end{tabular}} & 3500 & $4,59198 \mathrm{E}+16$ \\
\cline { 2 - 3 } & 1000 & $2,03236 \mathrm{E}+23$ \\
\hline \multirow{2}{*}{} & 2000 & $2,91072 \mathrm{E}+20$ \\
\hline
\end{tabular}

Sample C (porosity 55\%) with $1000 \mu \varepsilon$ loading shows the highest fatigue cycle of $2.03 \times 10^{23}$, and the greater the loading, the lower the number of failure cycles on the porous magnesium bone scaffold.

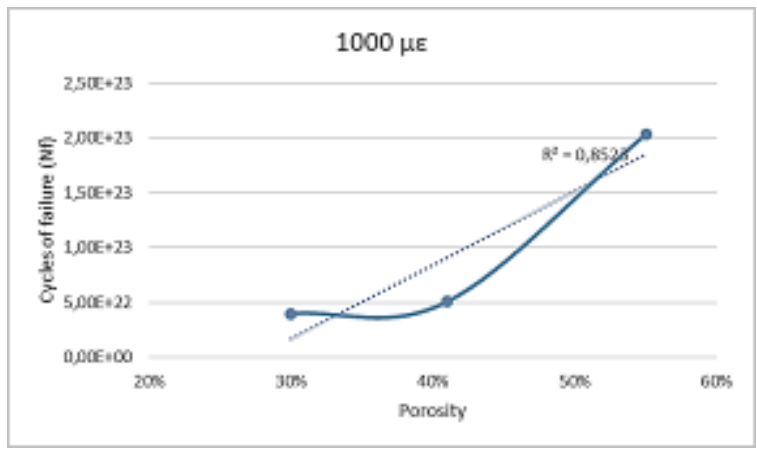

(a)

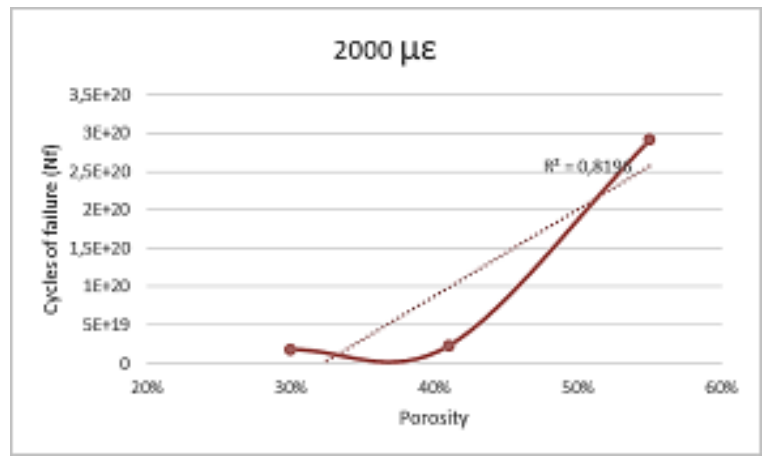

(b)

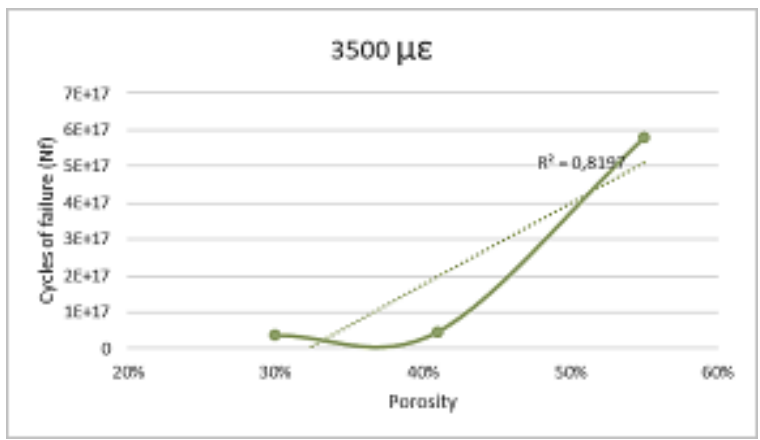

(c)

Figure 8 Cycles of failure vs porosity

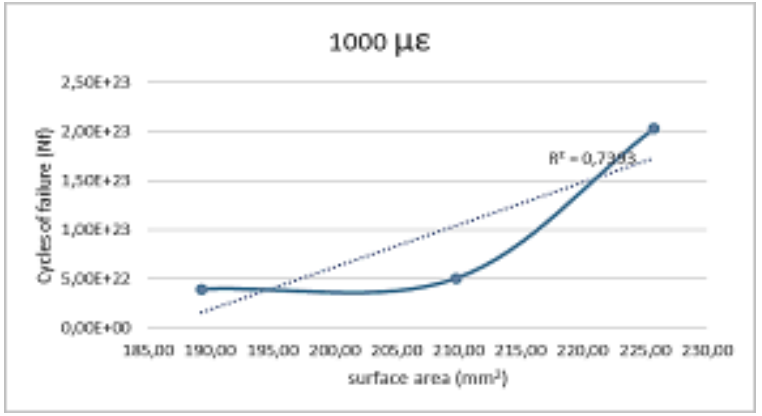

(a)

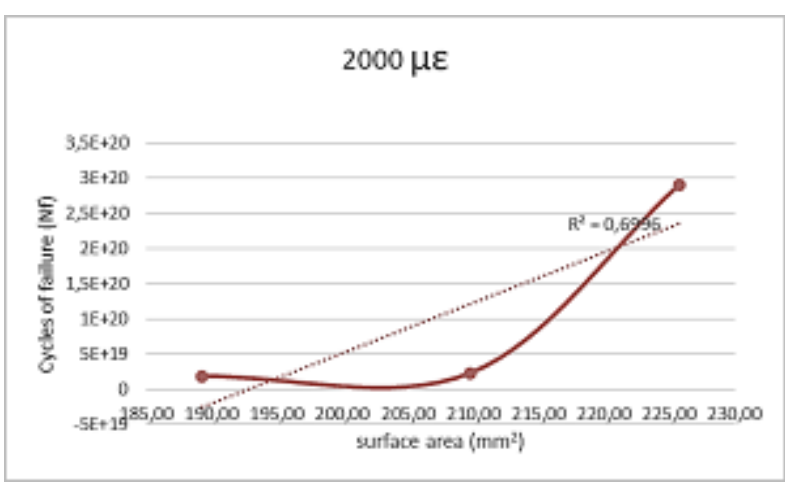

(b)

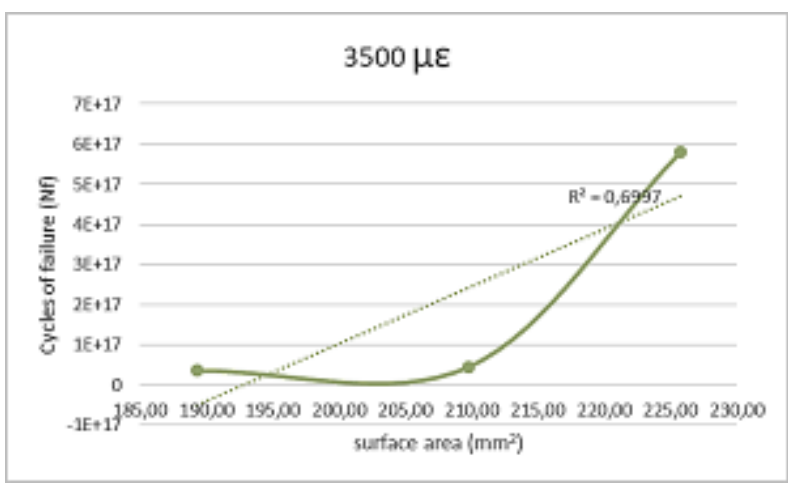

(c)

Figure 9 Cycles of failure vs surface area

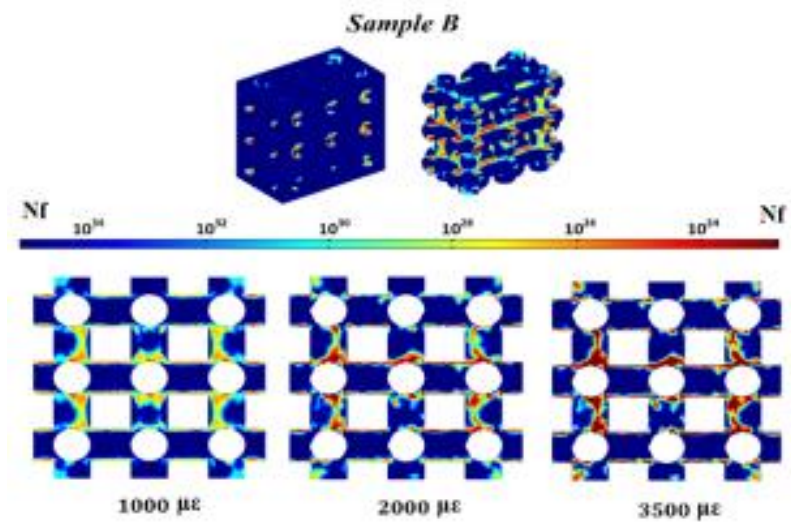

Figure 10 Contour of effective plastic strain predicted by FE simulations under axial load. 
It carried the prediction of fatigue failure in porous magnesium out using fatigue analysis software. The simulation results (see Figure 10) on sample B show that the loading rate affects the bone scaffold implant's significant plastic strain. A plot of the significant plastic strain shows that the greater the loading, the greater the significant plastic strain. It is indicated by the blue colour increasing to red. The area with a load of $3500 \mu \varepsilon$ that experienced the highest significant plastic strain.

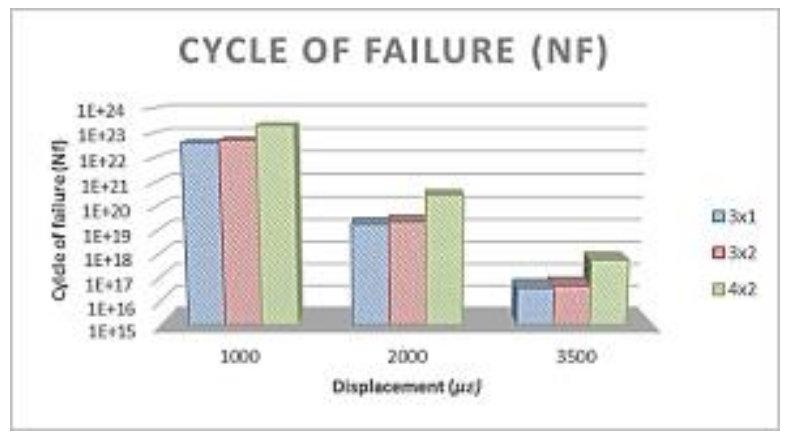

Figure 11 Diagram of the effect displacement on the cycles of failure $(\mathrm{Nf})$

Fatigue life analysis in this study uses a strain-life as a control, a mechanical change in the material shown by the decrease in the material's modulus to a plastic strain [16]. Several parameters affect fatigue life: a given load, surface area, and the fatigue parameters [17][18]. The load significantly given affects the fatigue life of the magnesium porous. Loading will affect the stress of the material; the greater the load given, the higher the stress that occurs so that the fatigue life in porous magnesium will be faster, as shown in Figure 11. The fatigue cycle value of porous magnesium implants with low displacement rates will have a greater fatigue cycle. Those with a higher displacement rate and morphological variations with low porosity have a large cycle of failure rate prediction of fatigue failure in porous magnesium that was carried out using fatigue analysis software. The simulation results (see Figure 10) on sample B show that the loading rate affects the bone scaffold implant's significant plastic strain. A plot of the significant plastic strain shows that the greater the loading, the greater the significant plastic strain. It is indicated by the blue colour increasing to red. The area with a load of $3500 \mu \varepsilon$ that experienced the highest significant plastic strain.

\section{CONCLUSIONS}

From the results and discussion above, we can conclude it as follows:

1) The fatigue life of porous magnesium bone scaffold is affected by the load applied. For sample C (porosity 55\%) with $1000 \mu \varepsilon$ loading shows the highest fatigue cycle of $2.03 \times 10^{23}$, and the greater the loading, the lower the number of failure cycles on the porous magnesium bone scaffold.

2) For sample A (porosity 30\%) with a load of 1000 $3500 \mu \varepsilon$, it produces the number of failure cycles from $3.99 \times 10^{22}-3.61 \times 10^{16}$.

3) Failure cycles for sample A (porosity 30\%) have a more significant fatigue cycle period than sample B (porosity $41 \%$ ) and sample C (porosity $55 \%$ ).

4) This study helps to understand the effect of variation of loading based on human physiological activity on porous magnesium bone scaffolding fatigue. The level of loading affects the bone scaffolding material's fatigue because the more significant the load applied will reduce the porous bone scaffold's fatigue life. Therefore, the bone scaffold structure against the fatigue cycle must be considered carefully for the initial degradation design, suitable for matching the healing or recovery process in medical applications.

\section{ACKNOWLEDGMENTS}

The DIPA of Public Service Agency of Universitas Sriwijaya 2020 funded this article's research/publication. SP DIPA-023.17.2.677515/2020, revision 01, on March 16, 2020. Under the Rector's Decree Number: 0687/UN9/SK.BUK.KP/2020, on July 15, 2020. We gratefully thank the Mechanical Engineering Department, Faculty of Engineering, Universitas Sriwijaya for their strong support of this study, along with the Medical Device and Technology Center (MEDITEC), Institute of Human-Centered and Engineering (iHumEn), Universiti Teknologi Malaysia for their encouragement and many fruitful discussions on this research.

\section{REFERENCES}

[1] F. S. Senatov, K. V. Niaza, A. A. Stepashkin, and S. D. Kaloshkin, "Low-Cycle Fatigue Behavior of 3d-Printed PLA-Based Porous Scaffolds," Compos. Part B Eng., vol. 97, pp. 193-200, 2016, doi: 10.1016/j.compositesb.2016.04.067.

[2] Y. Li et al., "Corrosion Fatigue Behavior of Additively Manufactured Biodegradable Porous Iron," Corros. Sci., vol. 156, no. January, pp. 106116, 2019, doi: 10.1016/j.corsci.2019.05.003.

[3] R. Hedayati et al., "Fatigue and Quasi-Static Mechanical Behavior of Bio-Degradable Porous Biomaterials Based on Magnesium Alloys," $J$. Biomed. Mater. Res. - Part A, vol. 106, no. 7, pp. 1798-1811, 2018, doi: 10.1002/jbm.a.36380.

[4] Y. Li et al., "Corrosion Fatigue Behavior of Additively Manufactured Biodegradable Porous Zinc," Acta Biomater., vol. 106, pp. 439-449, 2020, doi: 10.1016/j.actbio.2020.02.001. 
[5] A. P. Md Saad et al., "Dynamic Degradation of Porous Magnesium under a Simulated Environment of Human Cancellous Bone," Corros. Sci., vol. 112, pp. 495-506, 2016. doi: 10.1016/j.corsci.2016.08.017.

[6] S. P. Fritton, K. J. McLeod, and C. T. Rubin, "Quantifying the Strain History of Bone: Spatial Uniformity and Self-Similarity of Low-Magnitude Strains," J. Biomech., 2000, doi: 10.1016/S00219290(99)00210-9.

[7] M. E. Lynch and C. Fischbach, "Biomechanical Forces in the Skeleton and Their Relevance to Bone Metastasis: Biology and Engineering Considerations," Advanced Drug Delivery Reviews. 2014, doi: 10.1016/j.addr.2014.08.009.

[8] H. Basri et al., "Mechanical Degradation Model of Porous Magnesium Scaffolds under Dynamic Immersion," vol. 0, no. 0, pp. 1-11, 2019, doi: $10.1177 / 1464420719881736$.

[9] A. Zargarian, M. Esfahanian, J. Kadkhodapour, and S. Ziaei-Rad, "Numerical Simulation of the Fatigue Behavior of Additive Manufactured Titanium Porous Lattice Structures," Mater. Sci. Eng. C, 2016, doi: 10.1016/j.msec.2015.11.054.

[10] L. Polo-Corrales, M. Latorre-Esteves, and J. E. Ramirez-Vick, "Scaffold Design for Bone Regeneration," J. Nanosci. Nanotechnol., vol. 14, no. 1, pp. 15-56, 2014, doi: 10.1166/jnn.2014.9127.

[11] J. Rouwkema, N. C. Rivron, and C. A. van Blitterswijk, "Vascularization in Tissue Engineering," Trends in Biotechnology. 2008, doi: 10.1016/j.tibtech.2008.04.009.
[12] A. P. Md. Saad et al., "Dynamic Degradation of Porous Magnesium under a Simulated Environment of Human Cancellous Bone," Corros. Sci., pp. 1-12, 2016, doi: 10.1016/j.corsci.2016.08.017.

[13] A. P. Md Saad et al., "The Influence of Flow Rates on the Dynamic Degradation Behaviour of Porous Magnesium under a Simulated Environment of Human Cancellous Bone," Mater. Des., vol. 122, pp. 268-279, 2017, doi: 10.1016/j.matdes.2017.03.029.

[14] E. Birmingham, G. L. Niebur, L. M. McNamara, and P. E. McHugh, "An Experimental and Computational Investigation of Bone Formation in Mechanically Loaded Trabecular Bone Explants," Ann. Biomed. Eng., 2016, doi: 10.1007/s10439015-1378-4.

[15] A. P. Md Saad et al., "The Influence of Flow Rates on the Dynamic Degradation Behaviour of Porous Magnesium under a Simulated Environment of Human Cancellous Bone," Mater. Des., vol. 122 pp. 268-279, 2017, doi: 10.1016/j.matdes.2017.03.029.

[16] S. Suresh, "Fatigue of Materials, Cambridge Solid State Science Series," 1991.

[17] R. Basan, M. Franulović, I. Prebil, and N. ČrnjarićŽic, "Analysis of Strain-Life Fatigue Parameters and Behaviour of Different Groups of Metallic Materials," Int. J. Fatigue, vol. 33, no. 3, pp. 484491, 2011, doi: 10.1016/j.ijfatigue.2010.10.005.

[18] M. Kamaya and M. Kawakubo, "Loading Sequence ffect on Fatigue Life of Type 316 Stainless Steel," Int. J. Fatigue, vol. 81, pp. 10-20, 2015, doi: 10.1016/j.ijfatigue.2015.07.009. 